\title{
Lef1 may contribute to agenesis of the third molars in mice
}

\author{
Takehiko Shimizu $^{1,2}$, Eri Yokoi ${ }^{1}$, Takahiro Ichinosawa ${ }^{1}$, Yuri Kiguchi ${ }^{1}$, Fusae Ishida ${ }^{1}$, \\ Takahide Maeda ${ }^{1,2}$ \\ ${ }^{1}$ Department of Pediatric Dentistry, Nihon University School of Dentistry at Matsudo, Chiba, Japan \\ ${ }^{2}$ Nihon University Research Institute of Oral Science, Chiba, Japan \\ Email: shimizu.takehiko@nihon-u.ac.jp
}

Received 6 June 2013; revised 6 July 2013; accepted 21 July 2013

Copyright (C) 2013 Takehiko Shimizu et al. This is an open access article distributed under the Creative Commons Attribution License, which permits unrestricted use, distribution, and reproduction in any medium, provided the original work is properly cited.

\begin{abstract}
Tooth agenesis is the most common developmental anomaly of the human dentition. Epilepsy-like disorder (EL) mice, which have a $100 \%$ incidence of agenesis of the third molars, may be a good model for the genetic study of human tooth agenesis. Our previous congenic breeding strategy using EL mice confined a major locus for agenesis of M3, designated am3, within an approximately 1 Mega base pair (Mbp) interval on chromosome 3, which contains five known genes; Lef1, Hadh, Cyp2u1, Sgms2 and Papss1. The aim of this study was to identify the strongest candidate for am3 among the five genes using real-time PCR analysis. The tooth germs of M3 in the bud stage of EL and control mice were dissected out, and total RNA was extracted. In real-time PCR analysis, a significantly low level of expression of Lef 1 , which is one of the essential transcription factors for early tooth development, was observed in M3 of EL mice. In addition, a significantly low level of expression of $\mathrm{Fgf4}$, which is a direct transcriptional target for LEF1 in early tooth development, was observed in M3 of EL mice. Our results suggest that the cause of $\mathrm{M} 3$ agenesis of EL mice may be a low level of Lef1 expression in M3 in the bud stage of EL mice.
\end{abstract}

Keywords: Hypodontia; Gene Expression; EL Mice

\section{INTRODUCTION}

Tooth agenesis, the congenital absence of one or more teeth, is one of the most common craniofacial anomalies in humans. Its prevalence varies from $1.6 \%$ to $9.6 \%$ when the third molars are not considered [1]. The most frequently missing teeth are the third molars, which are absent in around $20 \%$ of the population, followed by the mandibular second premolars and maxillary lateral incisors [2]. It appears as both syndromic and non-syndro- mic/isolated features. The genes SHH [3], PITX2 [4], IRF6 [5] and p63 [6] have been associated with syndromic tooth agenesis. Mutations in MSX1 [7], PAX9 [8], AXIN2 [9], WNT10A [10] and the ectodermal dysplasia genes EDA [11], EDAR [12] and EDARADD [13] have been associated with non-syndromic tooth agenesis. However, in the majority of cases of tooth agenesis, the causes remain unknown [14-18], implying that other genes must be involved.

Inbred mice with homozygous alleles and a high degree of homology with human genes are frequently used in studies seeking to identify disease loci. Mice have a short life cycle that enables easy transgenerational observation and can be reared under the same conditions so that environmental factors can be kept almost constant, making them useful for genetic research. The normal mouse dentition is composed of one continuously growing incisor and three molars of limited growth in each quadrant. Congenital tooth agenesis is rarely observed in inbred mouse strains. However, the epilepsy-like disorder (EL) mouse, which was developed as an animal model for the study of epilepsy [19], has a $100 \%$ incidence of absence of M3 without any generalized craniofacial anomalies [20]. EL mice therefore may be a good model for the genetic study of agenesis of the third molar or other types of tooth agenesis in humans. Our previous genome-wide scan using $\mathrm{F}_{2}$ progeny from intercrosses between EL mice and the wild-type mice identified that alleles on chromosome 3 contribute to M3 agenesis in EL mice, suggesting independence from alleles of epilepsy [21]. Previous genes causing isolated tooth agenesis; Msx1, Pax9, Axin2, Wnt10a, Eda, Edar and Edaradd were clearly ruled out from the candidates for M3 agenesis in EL mice [22].

Recently, a major locus for agenesis of M3 (allele symbol am3) was defined in approximately the $1 \mathrm{Mbp}$ region of chromosome 3 using a congenic breeding strategy [23]. The region contained five known genes; Lef1, 
Hadh, Cyp2u1, Sgms2 and Papss1. The purpose of this study was to identify the strongest candidate for am3 among the five genes by gene expression analysis.

\section{MATERIALS AND METHODS}

\subsection{Mice}

EL mice were purchased from the Laboratory Animal Resource Bank at National Institute of Biomedical Innovation (Osaka, Japan) and MSM/Msf mice, a wildtype strain derived from Mus musculus molossinus progenitors, were obtained from the animal facilities at the National Institute of Genetics (Mishima, Japan). All animals were maintained and used in accordance with the guidelines of the Nihon University Intramural Animal Use. The experimental protocol was approved by the Institutional Animal Experiment Committee (No. AP11 MD029).

\subsection{Microdissection of Tooth Germ of M3 and Total RNA Isolation}

Ten EL mice and ten MSM mice were sacrificed under anesthesia on postnatal Day 3 (P3) when the tooth germ of M3 is in the bud stage. The heads were immediately embedded in Tissue-Tek OCT compound (Sakura Fineteck Japan, Tokyo, Japan). Serial sections of $30 \mu \mathrm{m}$ thickness were prepared using a Leica cryostat (Leica Microsystems, Wetzlar, Germany). Sections were dehydrated in $70 \%$ ethanol for $15 \mathrm{sec}$ and stained with $0.25 \%$ toluidine blue for $15 \mathrm{sec}$. The upper and lower tooth germs of M3 were dissected out using a needle under a dissection microscope, avoiding the tissues surrounding the tooth follicle (Figure 1). A total of $40 \mathrm{M} 3$ s from each strain were collected and stored in RNAlater ${ }^{\mathrm{TM}}$ RNA Stabilization Reagent (Qiagen, Tokyo, Japan) and total

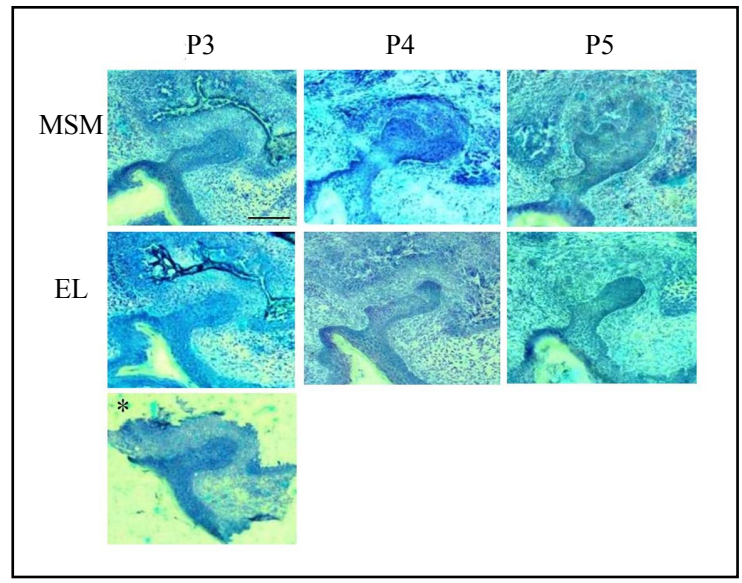

Figure 1. The third molar (M3) in EL and MSM/ms (MSM) at postnatal 3-day (P3), P4 and P5 (frontal section). * M3s were dissected out and collected from the sections for total RNA extraction. Bar indicates $100 \mu \mathrm{m}$.
RNA from sections was isolated using an RNeasy Total RNA kit (Qiagen, Tokyo, Japan), in accordance with the manufacturer's instructions. The quality and integrity of the RNA were checked by means of spectrophotometry and agarose-gel electrophoresis.

\subsection{Reverse-Transcriptase Polymerase Chain-Reaction (RT-PCR)}

Total RNA (100 ng) from tooth germs of M3 of EL mice and MSM mice was reverse-transcribed with the PrimeScript ${ }^{\circledR}$ High Fidelity RT-PCR kit (Takara, Tokyo, Japan). The reverse-transcribed cDNA was amplified with nine pairs for the nine genes of the PCR primers listed in Table 1. The 130.73 - 131.69 Mbp region on chromosome 3 for am 3 defined in EL congenic mice [23] contains five known genes; Lef1, Hadh, Cyp2u1, Sgms2 and Papss1, according to the information from Ensembl (http://asia.ensembl.org/index.html). In addition to these five genes, Wnt10a, which is upstream signaling molecule for Lef1 in early tooth development, and Fgf4 and Fgf3, which are downstream signaling molecules for Lef1 [24], were included in the analysis. Glyceraldehyde-3-phosphate dehydrogenase (Gapdh) was used as control. cDNAs were amplified by 30 cycles at $95^{\circ} \mathrm{C}$ for $30 \mathrm{sec}, 60^{\circ} \mathrm{C}$ for $30 \mathrm{sec}$, and $72^{\circ} \mathrm{C}$ for $30 \mathrm{sec}$ in the GeneAmp ${ }^{\circledR}$ PCR System 9700 (Applied Biosystems) and were analyzed by agarose gel electrophoresis. Products spanned at least one intron, so that cDNA products could be distinguished from potential genomic DNA products. The presence/absence and intensity of the PCR products for each gene were compared using the KODAK Molecular Imaging System (Kodak).

\subsection{Quantitative Real-Time PCR}

PCR amplification of cDNA was performed using Thermo

Table 1. Primer sets for RT-PCR and real-time PCR.

\begin{tabular}{|c|c|c|}
\hline Gene & Forward/ Reverse Primer (5'-3') & Size (bp) \\
\hline \multirow[t]{2}{*}{ Lef 1} & aaggcgatccccagaaggag & \\
\hline & agggtgttctctggecttgt & 190 \\
\hline \multirow[t]{2}{*}{ Hadh } & ttgegetccatgtcetcctc & \\
\hline & gactctcctcaattccettc & 194 \\
\hline \multirow[t]{2}{*}{ Сур 2 и 1} & ggctgaagtgttcagtgacc & \\
\hline & cgtatgcaaactcctcgatg & 188 \\
\hline \multirow[t]{2}{*}{ Sgms2 } & tcgaccgggtcaaatgggca & \\
\hline & gcattccgggcacaggtaac & 190 \\
\hline \multirow[t]{2}{*}{ Papss1 } & gggatgcagagagcaaccaa & \\
\hline & gtgtagcacggaatgccgtg & 194 \\
\hline \multirow[t]{2}{*}{ Wnt $10 a$} & tggagactcggaacaaagtc & \\
\hline & agcttccgacggaaagcttc & 193 \\
\hline \multirow{2}{*}{ Fgf4 } & gctgggectcaaaaggcttc & \\
\hline & ctgctcatggecacgaagaa & 192 \\
\hline \multirow[t]{2}{*}{ Fgf3 } & ctggccatgaacaagagagg & \\
\hline & tgccattcaccgacacgtac & 190 \\
\hline \multirow[t]{2}{*}{ Gapdh } & ggaagcccatcaccatcttc & \\
\hline & cgtggttcacacccatcaca & 203 \\
\hline
\end{tabular}


Scientific DyNAmo SYBR Green qPCR kits (Thermo Fisher Scientific, Kanagawa, Japan). The primers for real-time RCR were the same as those used for RT-PCR. The PCR program was as follows: initial denaturation at $95^{\circ} \mathrm{C}$ for $5 \mathrm{~min}$, followed by 40 cycles at $95^{\circ} \mathrm{C}$ for $30 \mathrm{sec}$, $60^{\circ} \mathrm{C}$ for $30 \mathrm{sec}$, and $72^{\circ} \mathrm{C}$ for $30 \mathrm{sec}$ in the DNA Engine OPTICON $^{\circledR}$ Continuous Fluorescence Detector (BioRad). Gene expression levels were normalized according to the level of Gapdh expression. Relative amounts of Gapdh mRNA in each sample were calculated from standard curves obtained by sequential dilution of total RNA prepared from M3 at P3. We used the Mann-Whitney test to compare the expression levels of five experiments in EL and MSM mice.

\section{RESULT}

Significant decreases in the quantity of Lef 1 mRNA in M3 of EL mice compared to that of MSM mice were detected in both RT-PCR and real-time PCR analysis (Figure 2). Significantly lower level of expression of Fgf4 and Fgf3 from M3 of EL mice than that of MSM mice was detected in both RT-PCR and real-time PCR analysis (Figure 3).

\section{DISCUSSION}

In a previous study, to determine the location of the am 3 locus in vivo, we produced EL congenic strains for am3 in which the restricted interval on chromosome 3 of EL mice was replaced by a wild-type-derived homologue. The congenic mice that were either heterozygous or homozygous for the wild-type-derived interval exhibited a significant decrease in the incidence of M3 agenesis. The results confined the am 3 locus to an approximately 1 Mbp region flanked by $A C 114668.1$ at $130.73 \mathrm{Mbp}$ and Dkk2 at 131.69 Mbp on chromosome 3, demonstrating the five candidate genes for am3; Lef1, Hadh, Cyp2u1, Sgms2 and Papss1 based on Ensembl information [23].

Lef1 is a cell-type-specific transcription factor that participates in the Wnt signaling pathway and Lef1 has a critical role in regulating tooth morphogenesis [25,26]. Lef ${ }^{-1}$ mouse embryos exhibited that the absence of LEF1 resulted in complete lack of tooth development [24]. LEF1 directly regulates Fgf4 gene expression, and FGF4 regulates the expression of Fgf3 in the dental mesenchyme to mediate the critical epithelial-mesenchymal interaction [27]. In the present study, significant decreases in the quantity of Lef1 mRNA in M3 of EL mice compared to that of MSM mice were found. In addition, a significantly lower level of expression of Fgf4 and Fgf3 from M3 of EL mice than that of MSM mice was detected, while there was no difference between EL and MSM mice in expression of Wnt $10 a$, which is a direct upstream signaling molecule for Lef1 in the bud stage.

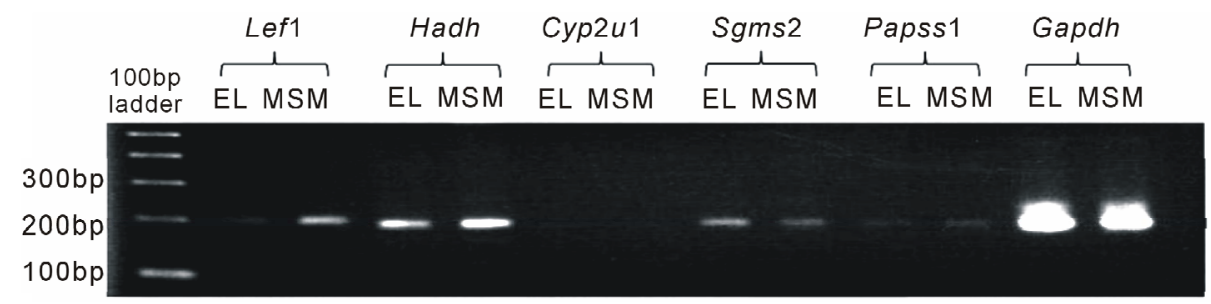

(a)

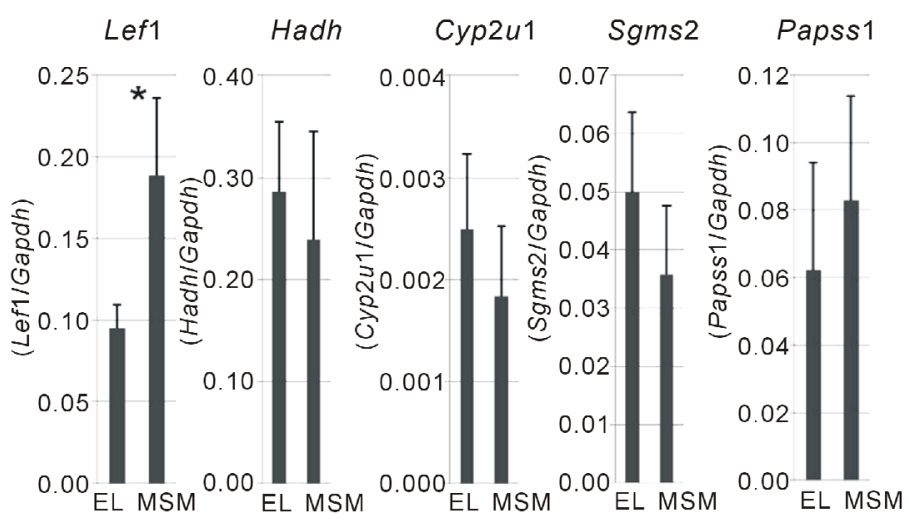

(b)

Figure 2. mRNA expression of Lef1, Hadh, Cyp2u1, Sgms2 and Papss1 in the third molar (M3) in the bud stage at postnatal 3-day. (a) RT-PCR analysis; (b) Real-time PCR analysis. The relative amounts of Lef1, Hadh, Cyp2u1, Sgms2 and Papss1 mRNA were divided by that of Gapdh. Results are expressed as the means of five experiments \pm SD. Significantly lower level of expression of Lef1 from M3 of EL mice than that of MSM mice was detected. ${ }^{*}<0.05$. 


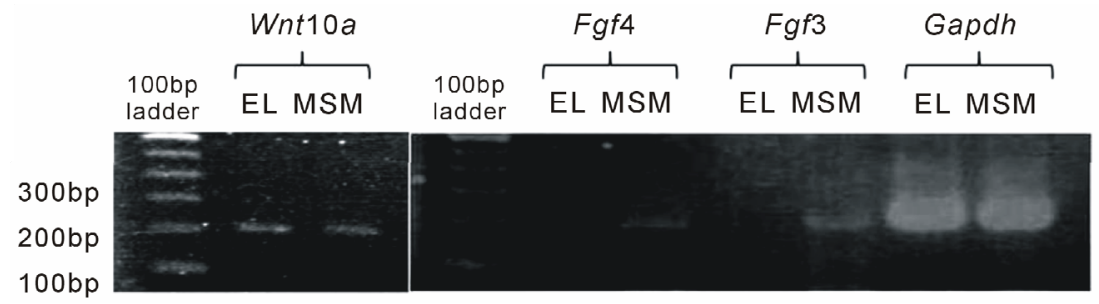

(a)
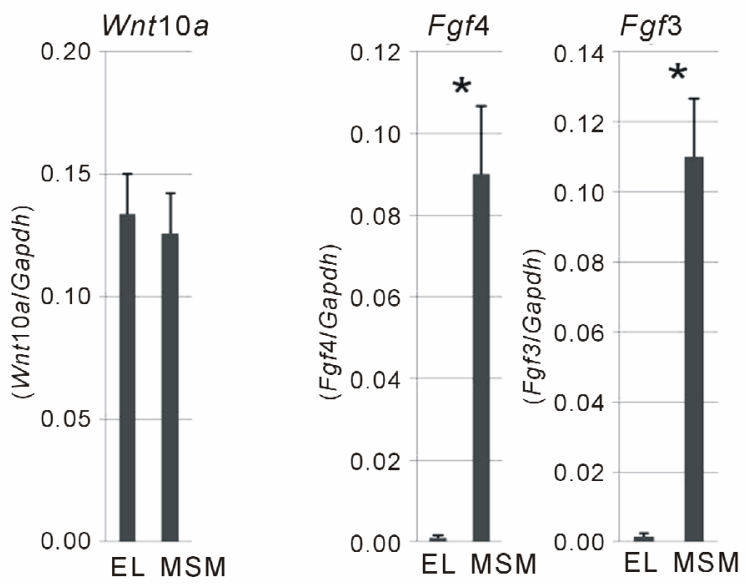

(b)

Figure 3. mRNA expression of Wnt10a, Fgf4 and Fgf3 in the third molar (M3) in the bud stage at postnatal 3-day. (a) RT-PCR analysis; (b) Real-time PCR analysis. The relative amounts of Wnt10a, Fgf4 and Fgf3 mRNA were divided by that of Gapdh. Results are expressed as the means of five experiments \pm SD. Significantly lower level of expression of Fgf4 and Fgf3 from M3 of EL mice than that of MSM mice was detected. ${ }^{*} \mathrm{p}<0.05$.

Interestingly, expression of these genes encoding signaling molecules in M3 of EL mice in the bud stage was reported to be very similar to that in the first molar (M1) in the bud stage of $L e f 1^{-/-}$mice. M1s in the late bud stage of Lef1 $1^{-/-}$embryos showed absence of expression of Fgf4 and Fgf3, but showed expression of Wnt10a [24]. This resemblance with previous findings suggested that Fgf4 might not be activated by LEF1 from M3 of EL mice, similar to the failure of Fgf4 activation in M1s of $L e f 1^{-1-}$ embryos. The decrease in Lef 1 may inhibit the activation of Fgf4 and Fgf3 in M3 in the bud stage of EL mice. Fgf4 and Fgf3, which are located on chromosome 7 , had been excluded from the list of potential candidates for am 3 based on the results of previous linkage analysis [21]. Our previous mutation analysis for the candidate genes did not find any mutation in the coding sequence of the five candidate genes from EL mice, and suggested that gene mutation is not responsible for M3 agenesis in EL mice [23]. Polymorphism in the other region of Lef1 may be the cause of the decreased expression of Lef1 in M3 of EL mice.

Other candidates for am 3 including Hadh (hydroxyacyl-coenzyme A dehydrogenase), Sgms2 (sphingomyelin synthase 2), Papss1 (3'-phosphoadenosine 5'-phospho- sulfate synthase 1) and Cyp2u1 (cytochrome P450, family 2 , subfamily u, polypeptide 1 ), show no evidence of association with hypodontia or early odontogenesis. Hadh plays a critical role in the mitochondrial beta-oxidation of short chain fatty acids and the gene mutation causes familial hyperinsulinemic hypoglycemia [28]. Sgms2 catalyzes the synthesis of sphingomyelin and diacylglycerol from phosphatidylcholine and ceramide, and Sgms $^{-/-}$mice exhibited difficulty of this conversion [29]. Papss1 is a bifunctional enzyme with both adenosine triphosphate sulfurylase and adenosine 5'-phosphosulfate kinase activity [30]. Сyp2u1 catalyzes the hydroxylation of arachidonic acid, docosahexaenoic acid and other long chain fatty acids [31]. In present study, we detected no significant difference in mRNA expression for Hadh, Sgms2, Cyp2u1 and Papss1 in M3 between EL and wildtype mice, suggesting no association with M3 agenesis.

Based on our gene expression analysis, we conclude that Lef 1 is the strongest candidate for am3, although the cause of the decrease of Lef1 expression in M3 of EL mice is still unclear. Unknown genes must be involved in various types of human tooth agenesis; therefore, Lef 1 might contribute to a form of tooth agenesis. Mutational analysis of LEF1 in non-syndromic tooth agenesis will 
be needed in subsequent experiments. The identification of am 3 in EL mice may provide clues to understanding a new mechanism of hypodontia, especially agenesis of the third molars, in humans. In the future, it may also be possible to apply the mechanism to the field of tooth regeneration.

\section{ACKNOWLEDGEMENTS}

This study was supported by JSPS KAKENHI Grant Number 2546 3199.

\section{REFERENCES}

[1] Boeira Jr., B.R. and Echeverrigaray, S. (2012) Polymorphism in the MSX1 gene in a family with upper lateral incisor agenesis. Archives of Oral Biology, 57, 14231428. doi:10.1016/j.archoralbio.2012.04.008

[2] Mostowska, A., Biedziak, B. and Jagodzinski, P.P. (2012) Novel MSX1 mutation in a family with autosomaldominant hypodontia of second premolars and third molars. Archives of Oral Biology, 57, 790-795. doi:10.1016/j.archoralbio.2012.01.003

[3] Belloni, E., Muenke, M., Roessler, E., Traverso, G., Siegel-Bartelt, J., Frumkin, A., Mitchell, H.F., DonisKeller, H., Helms, C., Hing, A.V., Heng, H.H., Koop, B., Martindale, D., Rommens, J.M., Tsui, L.C. and Scherer, S.W. (1996) Identification of Sonic hedgehog as a candidate gene responsible for holoprosencephaly. Nature Genetics, 14, 353-356. doi:10.1038/ng1196-353

[4] Semina, E.V., Reiter, R., Leysens, N.J., Alward, W.L., Small, K.W., Datson, N.A., Siegel-Bartelt, J., BierkeNelson, D., Bitoun, P., Zabel, B.U., Carey, J.C. and Murray, J.C. (1996) Cloning and characterization of a novel bicoidrelated homeobox transcription factor gene, RIEG, involved in Rieger syndrome. Nature Genetics, 14, 392399. doi:10.1038/ng1296-392

[5] Kondo, S., Schutte, B.C., Richardson, R.J., Bjork, B.C., Knight, A.S., Watanabe, Y., Howard, E., de Lima, R.L., Daack-Hirsch, S., Sander, A., McDonald-McGinn, D.M., Zackai, E.H., Lammer, E.J., Aylsworth, A.S., Ardinger, H.H., Lidral, A.C., Pober, B.R., Moreno, L., Arcos-Burgos, M., Valencia, C., Houdayer, C., Bahuau, M., Moretti-Ferreira, D., Richieri-Costa, A., Dixon, M.J. and Murray, J.C. (2002) Mutations in IRF6 cause Van der Woude and popliteal pterygium syndromes. Nature Genetics, 32, 285-289. doi:10.1038/ng985

[6] Celli, J., Duijf, P., Hamel, B.C., Bamshad, M., Kramer, B., Smits, A.P., Newbury-Ecob, R., Hennekam, R.C., Van Buggenhout, G., van Haeringen, A., Woods, C.G., van Essen, A.J., de Waal, R., Vriend, G., Haber, D.A., Yang, A., McKeon, F., Brunner, H.G. and van Bokhoven, H. (1999) Heterozygous germline mutations in the p53 homolog p63 are the cause of EEC syndrome. Cell, 99, 143-153. doi:10.1016/S0092-8674(00)81646-3

[7] Vastardis, H., Karimbux, N., Guthua, S.W., Seidman, J.G. and Seidman, C.E. (1996) A human MSX1 homeodomain missense mutation causes selective tooth agenesis. Nature Genetics, 13, 417-421. doi:10.1038/ng0896-417
[8] Stockton, D.W., Das, P., Goldenberg, M., D’Souza, R.N. and Patel, P.I. (2000) Mutation of PAX9 is associated with oligodontia. Nature Genetics, 24, 18-19. doi:10.1038/71634

[9] Lammi, L., Arte, S., Somer, M., Jarvinen, H., Lahermo, P., Thesleff, I., Pirinen, S. and Nieminen, P. (2004) Mutations in AXIN2 cause familial tooth agenesis and predispose to colorectal cancer. American Journal of Human Genetics, 74, 1043-1050. doi:10.1086/386293

[10] Kantaputra, P. and Sripathomsawat, W. (2011) WNT10A and isolated hypodontia. American Journal of Medical Genetics Part A, 155A, 1119-1122. doi:10.1002/ajmg.a.33840

[11] Tao, R., Jin, B., Guo, S.Z., Qing, W., Feng, G.Y., Brooks, D.G., Liu, L., Xu, J., Li, T., Yan, Y. and He, L. (2006) A novel missense mutation of the EDA gene in a Mongolian family with congenital hypodontia. Journal of Human Genetics, 51, 498-502. doi:10.1007/s10038-006-0389-2

[12] Azeem, Z., Naqvi, S.K., Ansar, M., Wali, A., Naveed, A.K., Ali, G., Hassan, M.J., Tariq, M., Basit, S. and Ahmad, W. (2009) Recurrent mutations in functionallyrelated EDA and EDAR genes underlie X-linked isolated hypodontia and autosomal recessive hypohidrotic ectodermal dysplasia. Archives of Dermatological Research, 301, 625-629. doi:10.1007/s00403-009-0975-1

[13] Bergendal, B., Klar, J., Stecksén-Blicks, C., Norderyd, J. and Dahl, N. (2011) Isolated oligodontia associated with mutations in EDARADD, AXIN2, MSX1, and PAX9 genes. American Journal of Medical Genetics Part A, 155A, 1616-1622. doi:10.1002/ajmg.a.34045

[14] Nieminen, P., Arte, S., Pirinen, S., Peltonen, L. and Thesleff, I. (1995) Gene defect in hypodontia: Exclusion of MSX1 and MSX2 as candidate genes. Human Genetics, 96, 305-308. doi:10.1007/BF00210412

[15] Arte, S., Nieminen, P., Pirinen, S., Thesleff, I. and Peltonen, L. (1996) Gene defect in hypodontia: Exclusion of EGF, EGFR, and FGF-3 as candidate genes. Journal of Dental Research, 75, 1346-1352. doi:10.1177/00220345960750060401

[16] Goldenberg, M., Das, P., Messersmith, M., Stockton, D.W., Patel, P.I. and D'Souza, R.N. (2000) Clinical, radiographic, and genetic evaluation of a novel form of autosomal-dominant oligodontia. Journal of Dental Research, 79, 1469-1475. doi:10.1177/00220345000790070701

[17] Scarel, R.M., Trevilatto, P.C., Di Hipolito Jr., O., Camargo, L.E. and Line, S.R. (2000) Absence of mutations in the homeodomain of the MSX1 gene in patients with hypodontia. American Journal of Medical Genetics, 92, 346-349. doi:10.1002/1096-8628(20000619)92:5<346::AID-AJMG 10>3.0.CO;2-A

[18] Gerits, A., Nieminen, P., De Muynck, S. and Carels, C. (2006) Exclusion of coding region mutations in MSX1, PAX9 and AXIN2 in eight patients with severe oligodontia phenotype. Orthodontics \& Craniofacial Research, 9, 129-136. doi:10.1111/j.1601-6343.2006.00367.x

[19] Imaizumi, K. and Nakano, T. (1964) Mutant stocks, strain El. Mouse News Letter, 31, 57. 
[20] Asada, Y., Shimizu, T., Matsune, K., Shimizu, K., Suzuki, Y., Takamori, K. and Maeda, T. (2000) Absence of the third molars in strain EL mice. Pediatric Dental Journal, 10, 19-22.

[21] Nomura, R., Shimizu, T., Asada, Y., Hirukawa, S. and Maeda, T. (2003) Genetic mapping of absence of the third molars in EL mice to chromosome 3. Journal of Dental Research, 82, 786-790. doi:10.1177/154405910308201005

[22] Shimizu, T., Han, J., Asada, Y., Okamoto, H. and Maeda, T. (2005) Localization of am 3 using EL Congenic Mouse Strains. Journal of Dental Research, 84, 315-319. doi: $10.1177 / 154405910508400404$

[23] Shimizu, T., Morita, W. and Maeda, T. (2013) Genetic mapping of agenesis of the third molars in mice. Biochemical Genetics. doi:10.1007/s10528-013-9602-0

[24] Kratochwil, K., Galceran, J., Tontsch, S., Roth, W. and Grosschedl, R. (2002) FGF4, a direct target of LEF1 and Wnt signaling, can rescue the arrest of tooth organogenesis in Lef1(-/-) mice. Genes \& Development, 16, 31733185. doi:10.1101/gad.1035602

[25] van Genderen, C., Okamura, R.M., Fariñas, I., Quo, R.G., Parslow, T.G., Bruhn, L. and Grosschedl, R. (1994) Development of several organs that require inductive epithelial-mesenchymal interactions is impaired in LEF-1-deficient mice. Genes \& Development, 8, 2691-2703. doi:10.1101/gad.8.22.2691

[26] Chen, J., Lan, Y., Baek, J.A., Gao, Y. and Jiang, R. (2009) Wnt/beta-catenin signaling plays an essential role in activation of odontogenic mesenchyme during early tooth development. Developmental Biology, 334, 174-185. doi:10.1016/j.ydbio.2009.07.015

[27] Sasaki, T., Ito, Y., Xu, X., Han, J., Bringas, P. Jr., Maeda, T. Slavkin, H.C., Grosschedl, R. and Chai, Y. (2005) LEF1 is a critical epithelial survival factor during tooth morphogenesis. Developmental Biology, 278, 130-143. doi:10.1016/j.ydbio.2004.10.021

[28] Clayton, P.T., Eaton, S., Aynsley-Green, A., Edginton, M., Hussain, K., Krywawych, S., Datta, V., Malingre, H.E., Berger, R. and van den Berg, I.E. (2001) Hyperinsulinism in short-chain L-3-hydroxyacyl-CoA dehydrogenase deficiency reveals the importance of beta-oxidation in insulin secretion. Journal of Clinical Investigation, 108, 457-465.

[29] Liu, J., Zhang, H., Li, Z., Hailemariam, T.K., Chakraborty, M., Jiang, K., Qiu, D., Bui, H.H., Peake, D.A., Kuo, M.S., Wadgaonkar, R., Cao, G. and Jiang, X.C. (2009) Sphingomyelin synthase 2 is one of the determinants for plasma and liver sphingomyelin levels in mice. Arteriosclerosis, Thrombosis, and Vascular Biology, 29, 850856. doi:10.1161/ATVBAHA.109.185223

[30] Sekulic, N., Dietrich, K., Paarmann, I., Ort, S., Konrad, M. and Lavie, A. (2007) Elucidation of the active conformation of the APS-kinase domain of human PAPS synthetase 1. Journal of Molecular Biology, 367, 488500. doi:10.1016/j.jmb.2007.01.025

[31] Choudhary, D., Jansson, I., Stoilov, I., Sarfarazi, M. and Schenkman, J.B. (2005) Expression patterns of mouse and human CYP orthologs (families 1-4) during development and in different adult tissues. Archives of Biochemistry and Biophysics, 436, 50-61.

doi:10.1016/j.abb.2005.02.001 